\title{
Recommendations when Designing to Address Procrastination: A Psychological Perspective
}

\begin{abstract}
Procrastination is a common behaviour that psychologists have found to have many negative consequences for both the individual and society. Standard psychological methods for addressing procrastination require significant time and effort, and consequently suffer a lack of adherence. This paper synthesises relevant psychological research to identify possible approaches designers could take in order to offer immediate aid to procrastinators. We suggest that an understanding of the psychological mechanisms underlying procrastination may inform and guide designers in creating interventions that shift some of the effort associated with undertaking tasks from the individual to the designed environment. In the paper, we draw on different psychological perspectives and strategies, highlighting how this information may be relevant and applicable for designers who aim to address and reduce procrastination behaviour through designed interventions.
\end{abstract}

\section{Keywords}

Procrastination, Design, Psychology, Motivation, Attention

\section{Introduction}

We all find ourselves putting off things that we would have benefited from doing earlier. For the many, procrastination is occasional -a few tasks without deadlines never get done and some tasks are done last minute - but generally the procrastination does not have a big impact. However for some populations like students, (85-95\% of whom report procrastination[1]), and those with high autonomy over their time [2], procrastination is prevalent and can have a large impact; affecting mental health and job performance. For 20 percent of the adult population, procrastination is habitual [3] impacting all aspects of life. The current psychological treatments for reducing procrastination take practice and effort [4], which can be particularly difficult for procrastinators. Almost half of those starting cognitive behavioural therapy, a common treatment, drop out before progress is made [5]. Designers may be able to help people reduce procrastination in a more immediate way by creating environments that counteract underlying causes. In a cross-disciplinary endeavour, this paper presents designers with the relevant psychological theories to consider when designing interactions that navigate the complexity of procrastination.

Putting tasks off does not necessarily constitute procrastination. There are many good reasons to delay 
a task: sometimes it is beneficial to wait in order to work with the latest information; sometimes another task is more important; sometimes a person needs a break first [6]. As Steel defines it, procrastination as the needless delay of a task to one's future detriment [7].

Procrastination is correlated with many undesirable outcomes. Procrastinators tend to have shorter-term, lower-paying jobs and make up nearly 60 percent of the unemployed [8]. Procrastinators often have poorer general mental health, lower self-esteem, lower self-efficacy, higher levels of neuroticism [7] increased stress [9], more long-term unhappiness [2], higher levels of self-sabotage[7], and higher levels of guilt due to breaking social norms [10]. In spite of this many people argue procrastination helps them: "I work better under pressure”; “it helps focus me”. However, empirical studies present a different story [9], [11], [12]. People make more mistakes, are less creative, and enjoy the overall experience less, both while they are delaying the task and when they are doing it under time pressure[13]. As Pychyl puts it, 'People don't work "better" under pressure; it's just they "only" work under pressure'[6].

Procrastination is also costly to society. In addition to 'putting work off', people procrastinate in many contexts of life, including health and wellbeing [14], life transitions such as retiring from work [15] and their personal lives [6]. Putting off health care choices [14], retirement savings [15], and on average procrastinating twenty-five percent of the work day [2], means that employers and taxpayers have to make up the difference. Arguably, if designers can help people address their procrastination, then both the individual and society will benefit.

Procrastination is often viewed as the result of laziness or lack of planning. However, as Steel's review of procrastination studies shows, procrastination results from failures in the self-regulation of emotion, attention, motivation, or engagement [7]. Psychologists typically address self-regulatory failure through cognitive behavioural therapies, restructuring negative thoughts and behaviour patterns [16], [17] teaching specific goal-directed behaviours [18], [19], implementation intentions [20] and Applied Behavioural Analysis [21].
Psychologists also employ cognitive strategies to increase self-efficacy, reduce negative thought cycles, self-handicapping, and irrational beliefs [19], [22]. These strategies all address the underlying regulatory failure but require significant time and effort to implement. Though 95 percent of procrastinators express a desire to change [9], many are discouraged and unable to adhere to therapeutic practice because the focus is on long-term change rather immediate aid[5]. This paper focuses on psychological approaches that designers may operationalise through the shaping of the physical environment, to offer people more immediate aid, as well as supporting the process of learning nonprocrastination. We are particularly concentrating on work-based tasks conducted at a computer. There are other ways of affecting how a task is done through design that are outside the scope of our consideration, for example, through: changing the task itself; changing the context of doing the task; changing the user. We focus here on making change through the design of the built environment and the interactive artefacts within it.

A review of the literature in conjunction with Blunt and Pychyl's work [23] highlights three types of task that people commonly procrastinate in the process of doing: - Tasks that cause anxiety: It might be that people are unsure of what is involved in the task, it might be that they are unsure of their ability to do it, or it might be the consequences of failing are high; but all of these cause anxiety that people want to avoid;

- Tasks that are tedious: These tasks may not be hard but require people to focus on something which isn't engaging or stimulating;

- Tasks that are effortful for low perceived reward: These tasks tend to be frustrating because, in spite of consuming a lot of effort, people get very little in return.

The cognitive view of procrastination as a failure in selfregulation means, in plain terms, that a procrastinator has been unable to make themselves do an undesirable task rather than do a more enjoyable one [7], [19]. The 'self-regulation failure' involved in procrastination can be described from a range of cognitive perspectives. The perspectives of willpower [24] and emotion regulation [10], [25] are highlighted in this paper in terms of their potential relevance for designers. 


\section{Willpower Perspective}

Psychologists have found that willpower is a finite resource [24], [26]. As people go through the day, their willpower is slowly used up, regardless of how it is used. To forgo distractions, people use up willpower. When people have many pleasurable distractions surrounding them, their willpower resources can be quickly depleted [26]. Technology design now provides many instant 'fun distractions' (e.g. smartphone game applications or social network sites), making it increasingly hard for procrastinators to attend to the task at hand. Their willpower is constantly being called upon and therefore is readily used up [6], [26], [27]. People also have many work-based distractions, with constant alerts making it easy to switch their attention away to simpler tasks [28], [29]. To address procrastination from the 'willpower perspective', designers need to look at how to reduce the amount of willpower required for each type of task. Willpower is used for both starting and maintaining task engagement.

The following will argue that designers can reduce the willpower requirements by:

- Making the task more desirable;

- Making the distractions less desirable;

- Using pre-decisions ('implementation intentions') to reduce periods of high demand on willpower.

\subsection{Making Tasks Seem More Desirable}

Feasibly, designers can increase the desirability of work tasks using several strategies. One strategy is to design for Flow conditions that are associated with enjoyable and intrinsically rewarding experiences [30]. Flow is commonly used by interaction designers to increase engagement. One aspect of Flow is knowing how well you are progressing [31]. We suggest that designed environments could provide people with feedback on their progress offering them the opportunity to feel good about it. This could be particularly effective for tasks which have long-term rewards.

Other key aspects of Flow are knowing 'what' and 'how' to do the task at hand and having the skills to accomplish it [31]. Designed interactions could help people break large tasks into more achievable steps helping increase their confidence and use their current skill levels in order to experience Flow. However, if
Flow is, fundamentally, about balancing challenge levels and individual skill levels[32], then it is important to acknowledge that sometimes people have to do tasks where this is not the case. Consequently, designers may need to consider another strategy. Rather than designing for Flow, they could increase task desirability by adapting the environment. Creating environments and interactions that users find desirable, may make tasks seem more enjoyable (or less disagreeable). Grading by a fire, with a hot drink steaming beside you seems more appealing than sitting in a hard chair, under fluorescent lights.

Starting a task is the most difficult part, and distractions can cause people to 'start' (re-engage) several times, even within one working session [6], [13]. Once people have started, the distractions and fears that were motivating them to procrastinate are less noticeable and they often find the task more pleasant than expected

[13]. By creating pleasurable interactions when initiating work designers may be able to use the salience of starting a task to increase task desirability. Experiments investigating cognitive abilities during dual tasks[33] indicate that interactions on different sensory channels (touch, site etc) to the main task can be processed without interfering with work[34]. We suggest that designers be careful not to create interactions that could present barriers to the work, and to consider how the experience could change over time, to avoid mundanity. We also predict that different solutions may be needed for 'starting a task' versus 'restarting after a distraction'.

Alternatively, designers could increase desirability through adding extrinsic rewards - a core component of gamification. Gamification aims to replicate the principles of gaming in non-gaming contexts and is commonly used by designers to increase engagement [35]. Extrinsic motivation is known to be helpful for changing behaviour [36]-[38] and can be attractive as it seems simple to design a reward system. Still, we advise designers to look carefully at schedules of reinforcement and interval times [39]; just a few milliseconds difference in timing rewards can make the difference between a successful system and a gimmick that loses its appeal. Notably, several studies indicate that extrinsic rewards may reduce intrinsic motivation [38], [40]. These results are not conclusive 
[41] but do highlight the complex relationships between different types of motivation. If using extrinsic rewards, we recommend considering social rewards that are concurrent to the tasks. Social rewards are hardwired for neurotypical people and are strong motivators [42]. We suggest offering social rewards during the task rather than the end, which could add to the task pressure consequently increase procrastination [10], [43]. We conjecture that concurrent rewards may mimic intrinsic motivation so people judge the task itself as enjoyable. This is why having a 'study buddy' can be so effective[44].

\subsection{Make the Distractions Less Desirable}

Removing Distractions. Designers may be able to reduce the required willpower by removing distractions, thus making them less desirable in the momentstudies show that "Out of sight, out of mind" isn't just a saying [6], [27], [45]. Online Procrastination guides [6], [46], [47] suggest using tools like website blockers or devices like Saent [48]. We conjecture that some people find it easier to work in public spaces [44], because the social norms limit some of the distractions. Interestingly, the act of removing the distractions can be as difficult as starting the task [49], particularly if a person's leisure and work share the same space. We propose that making distractions easy to remove and not associated with 'depriving oneself from pleasure' may be a helpful approach.

\section{Drowning Out Distractions. On the whole} external distractions can be removed or avoided. However, internal distractors (thoughts) cannot be simply removed. It takes willpower and effort not to follow a daydream or give in to self-doubt [6]. Stress narrows peoples' attentional focus [50-52] which can aid in ignoring internal distractors - an apparent benefit of working last minute. Unfortunately, this narrowed attentional focus can also result in poorer work outcomes and missed opportunities [51],

[52]. Designers may be able to recreate the positive aspects of narrow attentional focus by using sensory stimulation to 'drown out distractions'. According to the Perceptual Load Theory of attention processing, overloading perceptual inputs, may reduce vulnerability to distractions as there is no perceptual capacity left to process new information. Murphy, Groeger \& Greene
[53] give an excellent example: if a person is reading, a buzzing fly is likely to pull their attention away from their book. However, if the text is printed on mostly transparent paper with words on both sides, their sensory attention has to work hard to decipher the letters and the person is not likely to notice the fly. As long as the additional sensory inputs do not require cognitive attention, they generally do not interfere with cognitive performance [34], [54]. We conjecture that designed environments or artefacts could use sensory channels to pleasantly overwhelm a person's perceptual processing. The sensory inputs will need to be subtle enough not to divert attention from the primary task. For example, some people find sounds or music helpful when writing, but find songs with lyrics distracting. Companies like Fuzeinteriors [55] already place high important on the sensory experience of work spaces. And installations like Sensorium by Les M Studio [56] offer excellent examples of engaging touch.

Negative reinforcement. Alternatively, designers could use negative reinforcement as a motivation strategy [57-59]. Principles of negative reinforcement suggest a 'less pleasant environment' when people are 'off task', will make distractions less appealing and motivate people to focus. For example, when a person is 'off task', the chair they are sitting on could react becoming bumpy and less comfortable; and when attention is redirected to the task, the chair could become comfortable again.

When reviewing technologies that have been designed to address procrastination, we found negative reinforcement was a popular strategy. The smartphone application (app) "Yelling Mom" is a prime example; an alarm yells at the user until they do their work [60]. We identify issues with this approach, negative reinforcement becomes ineffective if it can easily be avoided: if the user can turn off the phone more easily than starting an assignment, then it is not likely to add motivation. Again we invite designers to consider carefully how negative reinforcers may become a barrier to the task: interventions where it easier to leave the workspace than to start work may, in fact, reinforce procrastination.

Scaffolding. It is possible, though not necessarily 
advisable, to use guilt as a negative reinforcer. Anderson suggests 'scaffolding' to force non-procrastination [45], [61]. He suggests creating environments that constantly remind people to do their work [61]. The presence of clocks, reminders and post-it notes makes it difficult to dismiss work or justify delay. Though quite possibly effective, we are wary of this approach, on the presumption that it is not necessarily conducive to a pleasurable work experience. Motivation from guilt, rather than enjoyment, will likely not boost positive emotional associations, which in turn would not increase intrinsic motivation. If designers were to consider using this motivation strategy, we suggest integrating periods of time free from pressure so people can experience positive downtime. Additionally, if the designed interventions 'invite' people to work, rather than 'pressure' them to, then the associated guilt may be reduced; but the reminders would still be there.

\subsection{Implementation Intentions (Pre-Decision Making)}

Finally, people can reduce willpower by spreading out the decision making. Implementation intentions is a psychological strategy employing pre-decisions to reduce spikes in cognitive load [62]. In the case of procrastination, the procrastinator would make the decision of when and what work to do beforehand. When the time comes to act, the pre-made decision requires less cognition. Implementation intentions are most effective when pre-decisions for distractors have also been made [63]. For example: "Even if I don't feel like starting, I won't open the news, not even for one article"; or "if Facebook is still open from yesterday, I will close it before looking at the timeline". These predecisions makes the cognitive process simpler when the event happens [64]. There is an opportunity for Designers to create physical reminders of pre-decisions. For example, a coffee table might automatically transform into a desk at the time the person intends to work. We expect that physical reminders will not only reinforce the pre-decisions but also make it harder for people to ignore them (similar to non-procrastination scaffolding).

\section{Emotion Regulation Perspective}

From an 'emotion regulation perspective', people tend to procrastinate to avoid the negative emotions they experience when approaching a task [25]. The three types of tasks evoke different emotions so they should be addressed in different ways.

\subsection{Effortful with Little Reward}

Tasks which are effortful with little reward evoke frustration. Such tasks could be helped by reframing them so their value and rewards are perceived better [50], [65]. How to reframe will vary. Herein, we recommend focusing on latent benefits of the task, or the accomplishment of doing the task. Anecdotally, people find that counting focused hours or progress is useful way of feeling good. We suggest designers could reward users with subtle changes in the environment as they work to highlight the passing of time or progress. (This also links with one of the aspects of Flow mentioned earlier [31]). When highlighting the passing of time, be careful it doesn't cause people to regret the hours they have put into unrewarding tasks.

Simple extrinsic rewards could also be used to make the outcome appear more worthwhile [36]. Though as mentioned earlier, there's a danger of the task becoming even harder when the rewards are no longer present. If designers were to employ gamification we propose carefully developing the rewards that fit the specific task and context: rewards that appear condescending will make the situation worse.

Conversely, a designer could address the frustration rather than the reward. Many people find grumbling and sharing their frustrations to be a release because it allows them to acknowledge their emotions [66], [67]. As long as this doesn't become rumination, wallowing, or a form of procrastinating, then we think a designed interaction for people to express their frustrations may help them move on to the task.

\subsection{Tedious Tasks}

Simple tasks that are tedious may be addressed by making the process itself more stimulating and enjoyable. The performance of tedious clerical tasks were improved by just adding the smell of peppermint to the environment [68]. Designers could engage a variety of sensory inputs, but should be wary of not slowing the process as this will increase the tedium. We also suspect that if people see the stimulation as 
gimmicky, they are likely to reclass the task as effortful with little reward.

The theory of optimal stimulation may be particularly useful for understanding people's behaviours during tedious tasks. Optimal stimulation states that people function best at a specific stimulation level [69], [70]. If people's stimulation is below this, they self-stimulate, similar to those with ADHD, seeking out new engaging activities or engaging their senses through movement and sound. If individuals are over stimulated then they withdraw, similar to those with autism, focusing on small details and creating 'white noise' sensations to drown out inputs. We expect that if designers can increase peoples' stimulation during tedious tasks, then their perceived boredom and their desire to redirect their attention will decrease.

\subsection{Anxiety}

People find tasks that cause anxiety particularly difficult. Generally, the best way to reduce the anxiety is for the person to start the task and discover that they are in fact capable. Interestingly, experience sampling studies have found that people feel happier when they are doing the task they have been putting off [13], [71]. In fact, people often wish they had started earlier so they "had more time to spend on the interesting aspects" [13]. The anxiety associated with task engagement is often not acute anxiety but low-level anxiety caused by uncertainty and the unknown. We identify that designers have two general approaches open to them. Either they can reduce the anxiety directly or can they distract people from it, aiding progress before they give up. We speculate, working last minute can be attractive because people no longer have time to worry.

To address anxiety directly, designers may use physiological approaches to activate the parasympathetic nervous system - encouraging people to breath more slowly and assume relaxed body postures [72], [73]. Other than exercise, this is one of the most reliable ways to reduce stress without addressing internal thoughts [68]. Many applications already exist to support relaxed breathing[74].

Further, environments could be designed to counteract the anxiety, by evoking associations of comfort and social support. Social support has been shown to be a significant moderator in stress [75]. A designer could create environments that remind people of their support networks during a task or they could provide communication channels to facilitate social support in work environments. There is also potential for design interventions to directly simulate social support. Touch is a vital aspect of human connection [76]. Social touch is as effective at communicating emotion as facial expressions and is stronger than verbal communication [76]. Social touch has been shown to increase compliance in some cases, and decrease anxiety, as well as raise serotonin levels and general health outcomes [76]. Simulating touch may allow people to experience the effects of social touch even without others. Several attempts have been made to simulate touch, particularly in autism research after Temple Grainden's hug machine[76]-[78]. These devices have not been empirically tested, although the techniques are widely used, and products such as weighted blankets are common in the autism community. There is an opportunity for designers to analyse the aspects of a comforting touch and then apply them through non-human mediums. Interactive furniture that subtly hugs the user may be help people feel supported and comforted. Designs like Hugvie $®[79]$ and TapTap [80] are used in the context of remote communication, and when empirically tested indicate drops in cortisol[81].

Distraction from emotions is a common (though not always healthy) way to regulate emotions. Pychyl and Sirois described procrastination as 'maladaptive emotion regulation'[25]. By avoiding the task, the procrastinator avoids negative emotions. We think helping people sidestep anxiety may be the most effective way to offer immediate aid. Over time this will build positive associations and hopefully reduce the anxiety. For procrastination, ignoring emotions can be positive because doing the task addresses one cause of the anxiety.

To distract from emotions, the theories of optimal stimulation [70] and perceptual load [53] suggest that people may be able to direct 'spare' attention towards low-level stimulation rather than their anxious thoughts. If designers were to combine emotion distraction with a social touch they may be able to create a low- 
level sensory stimulation that shifts attention, as well as giving an emotional boost. We would encourage designing two-way interactions that give both the user and object a prominent role. For example, A desk could react to a user's nervous fidgeting and by squeezing their hand simulating a social touch. Similar to TapTap [80].

\section{Developing Research and Conclusion}

The previous sections have contributed to design research by outlining the ways that a design space for addressing procrastination can be approached and informed by psychological perspectives. The general strategies proposed herein could be tailored for specific contexts and tasks. Our current research takes these strategies and applies them to the context of tertiary students working at home. We are focusing particularly on students because: firstly, they have the highest levels of procrastination [7]; secondly, because they are still learning to self-regulate and, if we can help develop positive strategies early, they will hopefully carry on in later life [82]: and thirdly, they do not have fixed work spaces which means they often work in spaces that are also for used for leisure. Spaces used for leisure are particularly hard to work in because they present habituated distractions and do not trigger work behaviours through associations [83]. We aim to tailor the design interventions for the different stages of task engagement. Interventions to start a task will differ from those to maintain a task. We also acknowledge that finishing is a crucial part of the process. At the end of a work session, people can feel enjoyment, pleasure and pride, which are key to increasing their positive associations with work. This has design implications, for emphasising the feeling of achievement through designed interactions.

This paper provides designers with a grounding in the some of the psychological theories of procrastination. It offers suggestions for how these insights can inform and guide the design of the physical environment and interactive artefacts within it, in order to address procrastination. Design strategies will differ depending on whether the designer addresses willpower or emotion regulation, and depending on what type of tasks they want to support. We hope that this cross disciplinary synthesis will provide a framework for design interventions that inspire and challenge tangible research outcomes.

\section{References}

1. Ellis, A. \& Knaus, W.J. (1977). Overcoming procrastination: or how to think and act rationally in spite of life's inevitable hassles. New York: Institute for Rational Living.

2. D'Abate, C.P. \& Eddy, E.R. (2007). Engaging in Personal Business on the Job: Extending the Presenteeism Construct, Hum. Resour. Dev. Q., 18 (3), pp. 361-383.

3. Harriott, J. \& Ferrari, J.R. (1996). Prevalence of Procrastination among Samples of Adults, Psychol. Rep., 78 (2), pp. 611-616.

4. Rozental, A. \& Carlbring, P. (2014). Understanding and treating procrastination: A review of a common selfregulatory failure, Psychology, 5 (13), pp. 1488-1502.

5. Fernandez, E., Salem, D., Swift, J.K. \& Ramtahal, N. (2015). Meta-analysis of dropout from cognitive behavioral therapy: Magnitude, timing, and moderators, J. Consult. Clin. Psychol., 83 (6), pp. 1108-1122.

6. Pychyl, T.A. (2013). Solving the Procrastination Puzzle: A Concise Guide to Strategies for Change, Reprint edition. New York: TarcherPerigee.

7. Steel, P. (2007). The nature of procrastination: A metaanalytic and theoretical review of quintessential selfregulatory failure., Psychol. Bull., 133 (1), pp. 65-94.

8. Nguyen, B., Steel, P. \& Ferrari, J.R. (2013). Procrastination's impact in the workplace and the workplace's impact on procrastination, Int. J. Sel. Assess., 21 (4), pp. 388-399.

9. Tice, D.M. \& Baumeister, R.F. (1997). Longitudinal Study of Procrastination, Performance, Stress, and Health: The Costs and Benefits of Dawdling, Psychol. Sci., 8 (6)

10. Giguère, B., Sirois, F.M. \& Vaswani, M. (2016). Chapter 9 Delaying Things and Feeling Bad About It? A Norm-Based Approach to Procrastination, in Procrastination, Health, and Well-Being, San Diego: Academic Press, pp. 189-212.

11. Michinov, N., Brunot, S., Le Bohec, O., Juhel, J. \& Delaval, M. (2011). Procrastination, participation, and performance in online learning environments, Comput. Educ., 56 (1),

12. Ferrari, J.R. (2001). Procrastination as self-regulation failure of performance: effects of cognitive load, self-awareness, and time limits on 'working best under pressure,' Eur. J. Personal., 15 (5), pp. 391-406.

13. Pychyl, T.A., Lee, J.M., Thibodeau, R. \& Blunt, A. (2000). Five days of emotion: An experience sampling study of undergraduate student procrastination., J. Soc. Behav. 
Personal., 15 (5), pp. 239-254

14. Sirois, F.M. (2004). Procrastination and intentions to perform health behaviors: The role of self-efficacy and the consideration of future consequences, Personal. Individ. Differ., 37 (1)

15. O'Donoghue, T. \& Rabin, M. (1999). Incentives for Procrastinators, Q. J. Econ., 114 (3)

16. Bennett-Levy, J. (2003). Mechanisms Of Change In Cognitive Therapy: The Case Of Automatic Thought Records And Behavioural Experiments, Behav. Cogn. Psychol., 31(3)

17. Virués-Ortega, J. \& Haynes, S.N. (2005). Functional analysis in behavior therapy: Behavioral foundations and clinical application, Int. J. Clin. Health Psychol., 5 (3)

18. Locke, E.A. \& Latham, G.P. (2002). Building a practically useful theory of goal setting and task motivation: A 35-year odyssey., Am. Psychol., 57 (9), pp. 705-717.

19. Van Eerde, W. (2000). Procrastination: Self-regulation in Initiating Aversive Goals, Appl. Psychol., 49 (3), pp. 372-389.

20. Gollwitzer, P.M., Sheeran, P., Michalski, V. \& Seifert, A.E. (2009). When Intentions Go Public: Does Social Reality Widen the Intention-Behavior Gap?, Psychol. Sci., 20 (5)

21. Rozental, A. \& Carlbring, P. (2013). Internet-Based Cognitive Behavior Therapy for Procrastination: Study Protocol for a Randomized Controlled Trial, JMIR Res. Protoc., 2(2)

22. Hayes, S.C., Levin, M.E., Plumb-Vilardaga, J., Villatte, J.L. \& Pistorello, J. (2013). Acceptance and Commitment Therapy and Contextual Behavioral Science: Examining the Progress of a Distinctive Model of Behavioral and Cognitive Therapy, Behav. Ther., 44 (2)

23. Blunt, A.K. \& Pychyl, T.A. (2000). Task aversiveness and procrastination: A multi-dimensional approach to task aversiveness across stages of personal projects, Personal. Individ. Differ., 28 (1), pp. 153-167.

24. Baumeister, R.F., Vohs, K.D. \& Tice, D.M. (2007). The Strength Model of Self-Control, Curr. Dir. Psychol. Sci., 16 (6), pp. 351-355.

25. Pychyl, T.A. \& Sirois, F.M. (2016). Chapter 8 Procrastination, Emotion Regulation, and Well-Being, in Procrastination, Health, and Well-Being, San Diego: Academic Press,

26. Schmeichel, B.J. \& Baumeister, R.F. (2010). Effortfull Attention Control, in Effortless attention: a new perspective in the cognitive science of attention and action, Cambridge, Mass: The MIT Press.

27. Steel, P. (2012). The Procrastination Equation: How to Stop Putting Things Off and Start Getting Stuff Done, Reprint edition. New York, NY: Harper Perennial.
28. Adamczyk, P.D. \& Bailey, B.P. (2004). If Not Now, when?: The Effects of Interruption at Different Moments Within Task Execution, in Proceedings of the SIGCHI Conference on Human Factors in Computing Systems, New York, NY, USA, pp. 271-278.

29. Zijlstra, F.R.H., Roe, R.A., Leonora, A.B. \& Krediet, I. (1999) Temporal factors in mental work: Effects of interrupted activities, J. Occup. Organ. Psychol., 72 (2), pp. 163-185.

30. Csikszentmihalyi, M. (2000). Beyond boredom and anxiety. CA, US: Jossey-Bass.

31. Schaffer, O. (2013). Crafting Fun User Experiences: A Method to Facilitate Flow, White Paper.

32. Nakamura, J. \& Csikszentmihalyi, M. (2014). The Concept of Flow, in Flow and the Foundations of Positive Psychology: The Collected Works of Mihaly Csikszentmihalyi, M. Csikszentmihalyi, Ed. Dordrecht: Springer Netherlands, pp. 239-263.

33. Cohen, R.A. (2014). Cognitive Psychology of Attention: Foundations, in The Neuropsychology of Attention, Springer, Boston, MA, pp. 19-53.

34. Navon, D. (1985). Attention division or attention sharing, Atten. Perform. XI, 133, p. 146.

35. Hamari, J. \& Koivisto, J. (2015). Why do people use gamification services?, Int. J. Inf. Manag., 35 (4), pp. 419-431.

36. Deci, E.L. \& Ryan, R.M. (1985). Cognitive evaluation theory. In Intrinsic motivation and self-determination in human behavior (pp. 43-85). Springer, Boston, MA.

37. Ryan, R.M. \& Deci, E.L. (2000). Intrinsic and Extrinsic Motivations: Classic Definitions and New Directions, Contemp. Educ. Psychol., 25 (1), pp. 54-67.

38. Lepper, M.R. \& Henderlong, J. (2000).Turning "play" into "work" and "work" into "play": 25 Years of research on intrinsic versus extrinsic motivation, in Intrinsic and Extrinsic Motivation, C. Sansone \& J. M. Harackiewicz, Eds. San Diego: Academic Press

39. Ferster, C.B. \& Skinner, B.F. (1957). Schedules of reinforcement. East Norwalk, CT, US: Appleton-CenturyCrofts.

40. Deci, E.L. (1971). Effects of Externally Mediated Rewards on Intrinsic Motivation, J. Pers. Soc. Psychol.

41. Wiersma, U.J. (1992). The effects of extrinsic rewards in intrinsic motivation: A meta-analysis, J. Occup. Organ. Psychol., 65 (2), pp. 101-114.

42. Chevallier, C., Kohls, G., Troiani, V., Brodkin, E.S. \& Schultz, R.T. (2012). The social motivation theory of autism., Trends Cogn. Sci., 16 (4), pp. 231-239.

43. Fee, R.L. \& Tangney, J.P. (2000). Procrastination: A means of 
avoiding shame or guilt?, J. Soc. Behav. Personal., 15 (5), pp. 167-184.

44. Mewburn, I., Osborne, L. \& Caldwell, G.A. (2014). Shut up and write! Some surprising uses of cafes and crowds in doctoral writing, in Writing Groups for Doctoral Education and Beyond : Innovations in Theory and Practice, Aitchison \& Guerin, Eds. Routledge

45. Heath, J. \& Anderson, J. (2010). Procrastination and the Extended Will, in The Thief of Time, C. Andreou \& M. D. White, Eds. Oxford University Press, pp. 233-253.

46. wikiHow. How to Stop Procrastinating, wikiHow. [Online]. Available: https://www.wikihow.com/Stop-Procrastinating. [Accessed: Feb-2018].

47. Steel, P. (2015). Living in the Candy Store, Psychology Today. https://www.psychologytoday.com/blog/the-procrastinationequation/201507/living-in-the-candy-store.

48. Focus like a pro and maximize productivity with Saent. Available: https://www.saent.com/.

49. Kroese, F.M., Nauts, S., Kamphorst, et al. (2016). Bedtime Procrastination: A Behavioral Perspective on Sleep Insufficiency, in Procrastination, Health, and Well-Being, F. M. Sirois \& T. A. Pychyl, Eds. San Diego: Academic Press, pp. 93-119.

50. Matthews, G., Warm, J.S., Reinerman, L.E., et al. (2010). Task Engagement, Attention, and Executive Control, in Handbook of Individual Differences in Cognition: Attention, Memory, and Executive Control, A. Gruszka, G. Matthews, \& B. Szymura, NY: Springer.

51. Najmi, S., Kuckertz, J.M. \& Amir, N. (2012). Attentional impairment in anxiety: inefficiency in expanding the scope of attention, Depress. Anxiety, 29 (3), pp. 243-249.

52. Eysenck, M.W., Derakshan, N., Santos, R. \& Calvo, M.G. (2007). Anxiety and cognitive performance: The attentional control theory, Emotion, pp. 10-1037.

53. Murphy, G., Groeger, J.A. \& Greene, C.M. (2016). Twenty years of load theory-Where are we now, and where should we go next?, Psychon. Bull. Rev. N. Y., 23 (5), pp. 1316-1340.

54. Schneider, W. \& Shiffrin, R.M. (1977). Controlled and automatic human information processing: I. Detection, search, and attention., Psychol. Rev., 84 (1), pp. 1-66.

55. Sensory Experience | Workspace Design, Fuze Business Interiors. .

56. Sensorium Les M Studio. (2012). http://www.lesmdesignstudio.com/en/projets/sensorium/

57. Romani, P.W. et al. (2016). Relations between rate of negative reinforcement and the persistence of task completion, J. Appl. Behav. Anal., 49 (1), pp. 122-137.

58. Crowley, M.J., Wu, J., Bailey, C.A. \& Mayes, L.C. (2009).
Bringing in the negative reinforcements: The avoidance feedback-related negativity, NeuroReport Rapid Commun. Neurosci. Res., 20 (17), pp. 1513-1517.

59. Sailer, M., Hense, J., Mandl, H. \& Klevers, M. (2013). Psychological Perspectives on Motivation through Gamification, IxD\&A, 19, pp. 28-37.

60. Gadget Hacks. Use YellingMom Reminders on Your iPhone to Never Forget Another Chore or Task Again [How-To].

61. Anderson, J.H. (2016). Chapter 3 - Structured Nonprocrastination: Scaffolding Efforts to Resist the Temptation to Reconstrue Unwarranted Delay, in Procrastination, Health, and Well-Being, F. M. Sirois \& T. A. Pychyl, Eds. San Diego: Academic Press, pp. 43-63.

62. Gollwitzer, P.M. \& Sheeran, P. (2006). Implementation Intentions and Goal Achievement: A Meta $\square$ analysis of Effects and Processes, in Advances in Experimental Social Psychology, 38, Academic Press, pp. 69-119.

63. Gollwitzer, P. \& Brandstätter, V. (1997). Implementation Intentions and Effective Goal Pursuit, First Publ J. Personal. Soc. Psychol. 7319971 Pp 186-199, 73.

64. Gollwitzer, P.M. (1999). Implementation intentions: Strong effects of simple plans, Am. Psychol., 54 (7), pp. 493-503.

65. Shuck, B. \& Rose, K. (2013). Reframing Employee Engagement Within the Context of Meaning and Purpose: Implications for HRD, Adv. Dev. Hum. Resour., 15 (4),

66. Kowalski, R.M. (2002). Whining, griping, and complaining: Positivity in the negativity, J. Clin. Psychol., 58 (9), pp. 1023-1035.

67. Edwards, D. (2005). Moaning, whinging and laughing: the subjective side of complaints, Discourse Stud., 7 (1), pp. $5-29$.

68. Seaward, B.L. (2017). Managing Stress. Jones \& Bartlett Learning.

69. Zentall, S. (1975). Optimal stimulation as theoretical basis of hyperactivity, Am. J. Orthopsychiatry, 45 (4), pp. 549-563.

70. Zentall, S.S. \& Zentall, T.R. (1983). Optimal stimulation: a model of disordered activity and performance in normal and deviant children, Psychol. Bull., 94 (3), pp. 446-471.

71. Sumaya, I.C. \& Darling, E. (2018). Procrastination, Flow, and Academic Performance in Real Time Using the Experience Sampling Method, J. Genet. Psychol., 179 (3),

72. Harris, V.A., Katkin, E.S., Lick, J.R. \& Habberfield, T. (1976). Paced Respiration as a Technique for the Modification of Autonomic Response to Stress, Psychophysiology, 13 (5), pp. 386-391.

73. Andreae, H. (2017). Relax: Students' Designs for Stress', in Design4Health, Melbourne. Proceedings of the Fourth International Conference on Design4Health 2017, Melbourn. 
74. Juhasz, a. (2018). The 10 Best Anxiety Relief Apps, The cut. [Online]. Available: https://www.thecut.com/article/the-10best-anxiety-relief-apps.html. [Accessed: 3-2019].

75. Cobb, S. (1976). Social support as a moderator of life stress, Psychosom. Med., 38 (5),

76. Field, T. (2010). Touch for socioemotional and physical wellbeing: A review, Dev. Rev., 30 (4), pp. 367-383.

77. Grandin, T. (1992). An Inside View of Autism, in HighFunctioning Individuals with Autism, E. Schopler \& G. B. Mesibov, Eds. Boston, MA: Springer US, pp. 105-126.

78. Lang, R. et al. (2012). Sensory integration therapy for autism spectrum disorders: A systematic review., Res. Autism Spectr. Disord., 6 (3), pp. 1004-1018.

79. Minato, T., Nishio, S. \& Ishiguro, H. Evoking an Affection for Communication Partner by a Robotic Communication Medium, p. 1.

80. Bonanni, L., Vaucelle, C., Lieberman, J. \& Zuckerman, O. (2006). Taptap: a haptic wearable for asynchronous distributed touch therapy, in In CHI '06: CHI '06 extended abstracts on Human factors in computing systems, pp. 580-585.

81. Sumioka, H., Nakae, A., Kanai, R. \& Ishiguro, H. (2013). Huggable communication medium decreases cortisol levels, Sci. Rep., 3, p. 3034.

82. Berkman, E. (2017). Self-regulation training, in Handbook of Self-Regulation, Third Edition: Research, Theory, and Applications, 3rd ed., New York: Guilford.

83. Nippert-Eng, C.E. (2008). Home and Work: Negotiating Boundaries through Everyday Life. University of Chicago Press. 